\title{
PROPOSAL OF THREE-PHASE HIGH FREQUENCY TRANSFORMER ISOLATION UPS TOPOLOGIES
}

\author{
Carlos G. C. Branco, René P. Torrico-Bascopé, Cícero M. T. Cruz, Francisco K. A. Lima \\ Universidade Federal do Ceará \\ Departamento de Engenharia Elétrica \\ Campus do Pici, Bloco: 705, CEP: 60.455-760, Caixa Postal 6001, Fortaleza-CE-Brasil \\ E-mails: \{gustavo, rene, cicero, klima\}@dee.ufc.br
}

\begin{abstract}
A family of double conversion three-phase uninterruptible power system with power factor correction and high-frequency transformer (HFT) isolation topologies is presented in this work. This might be an alternative compared to large conventional UPS systems that are based in bulky transformers that operates in the grid frequency. These systems are suitable for operation with line-to-line input voltages equal to 220 $V$ or $380-V$. For both input voltages, the proposed converter has almost the same efficiency processing the same output power. The three-phase HFT UPS used for further analysis is composed by single-phase chopper modules, one three-phase boost module, and one threephase inverter. The relevant features are soft commutation of the controlled switches in the chopper stage, simple control strategy that can be implemented with well-known integrated circuits (IC), and the use of few batteries in series due to the same reference of the step-up stages. Principle of operation of the chosen system for experimental validation, implemented control strategy and experimental results obtained for a $15 \mathrm{kVA}$ prototype are presented.
\end{abstract}

Keywords - High-frequency Transformer Isolation, Power Factor Correction (PFC), Three-phase Uninterruptible Power Supply.

\section{INTRODUCTION}

Nowadays uninterruptible power systems (UPS) are recommended not only to provide reliable power for critical loads but also to serve as support for implementation of distributed generation (DG), regarding the interfacing of renewable energy sources or as distributed energy storage systems integrated to the grid. Due to the DG concept growing in importance, is expected that the future utility line will be formed by distributed energy resources and small grids interconnected between them [1]-[3].

The variable nature of some renewable energy systems, such as photovoltaic (PV) or wind energy require the utilization of an additional energy system, when is desired to supply the local loads with reliable power. In this situation distributed energy storage systems can be used, such as flow batteries, fuel cells, flywheels, superconductor inductors, or compressed air devices [4].

The true on-line UPS configuration is recommended for most of applications due to its immunity to the most of

Artigo submetido em 02/05/2011. Revisado em 09/11/2011. Aceito para publicação em 17/11/2011 por recomendação do editor João Onofre P. Pinto. disturbances from the grid. This is the most reliable UPS configuration due to its capacitor tank in the DC bus and it also provides total independence between input and output voltage amplitude and frequency, and, thus, high output voltage quality can be obtained [5].

Most of true on-line UPS operates with a low frequency transformer using a silicon-steel core. In this configuration, it is normally required an isolating transformer for proper operation of the bypass circuit and also to improve reliability of the system, since the transformer offers a galvanic isolation to the load from undesirable disturbances of the grid. Such transformer is placed at the output employing the delta/wye connection [6]. The addition of such magnetic component increases both weight and volume, and also adds cost and difficulties in the transportation to the installation site.

Transformerless UPS incorporating a common neutral bus line could be a solution to improve power conversion efficiency, volume and weight reduction [7]-[10]. Although this UPS topology offered a way to obtain these advantages, these types don't provide isolating to critical loads, such as, medical instruments.

The high frequency transformer isolation (HFT) technology could be used when the desired feature of the UPS is weight and volume reduction of the transformer isolated based equipment [11]-[17]. In order to implement this technique is required the addition of more power conversion stages. Thus, it reaches a final energy conversion efficiency lower compared to conventional available UPS solutions.

Considering the constant development of semiconductor industry, advanced technology on topology, core of transformer, and soft switching is expected that this solution could be used in the next generation UPS or solid-state transformer (SST) applications [18].

In this work the three-phase HFT based UPS technology were considered in the topologies proposals in order to obtain final equipment with a smaller size and weight. The concept is to use modular converters for higher output power combining the advantages of single-phase topologies and avoiding the direct connection of the battery bank through the dc-link.

\section{HFT UPS ARCHITECTURES REVISION}

Several HFT UPS topologies were proposed in the literature but almost of them are single phase approaches [11], [15], [16], [17]. For this work, the literature revision focus was the three-phase HFT converters. A common important feature is the power factor correction and the reduced voltage stress across the active semiconductors. 
Such features can be achieved by using suitable topologies and control techniques.

In [19]-[22] are proposed three-phase rectifiers with one transistor based on flyback and Cuk converters operating in discontinuous and continuous conduction modes, that can be used for the development of UPS topologies. The advantages are the simple structure of power circuit and of the control circuit. Drawbacks of these proposals are the output power limitation and low efficiency. For high power systems, in [23] was proposed some three-phase rectifiers.

These rectifiers are named Vienna rectifier II. They are also suitable for applications such as telecommunication rectifiers and UPS systems. As main features it presents a simple structure of the power and control circuit (the described control can be realized in purely analog fashion) and as drawbacks an unfavorable transformer dimensioning for a wide variation range of the input and output voltages.

Other technique found to implement three-phase rectifiers is the association of single-phase high frequency isolated converters, also, named three-phase rectifier based on modular technique was proposed in [24] and [25]. The first one was based on high frequency isolated series resonant converters, and the second one was given by two boost stages and full-bridge converters. The modular circuit arrangement improves the hardware implementation and simplifies the control circuitry. However, such proposals are intended for telecommunications applications that differ from the UPS specifications.

In order to obtain the proposed UPS topology is important to analyze the block diagrams shown in Figures 1 and 2. Such simplified blocks propose power converters stages with modularity characteristic. Due to this fact a higher power HFT UPS system could be implemented by using semiconductor power modules that improves power density.

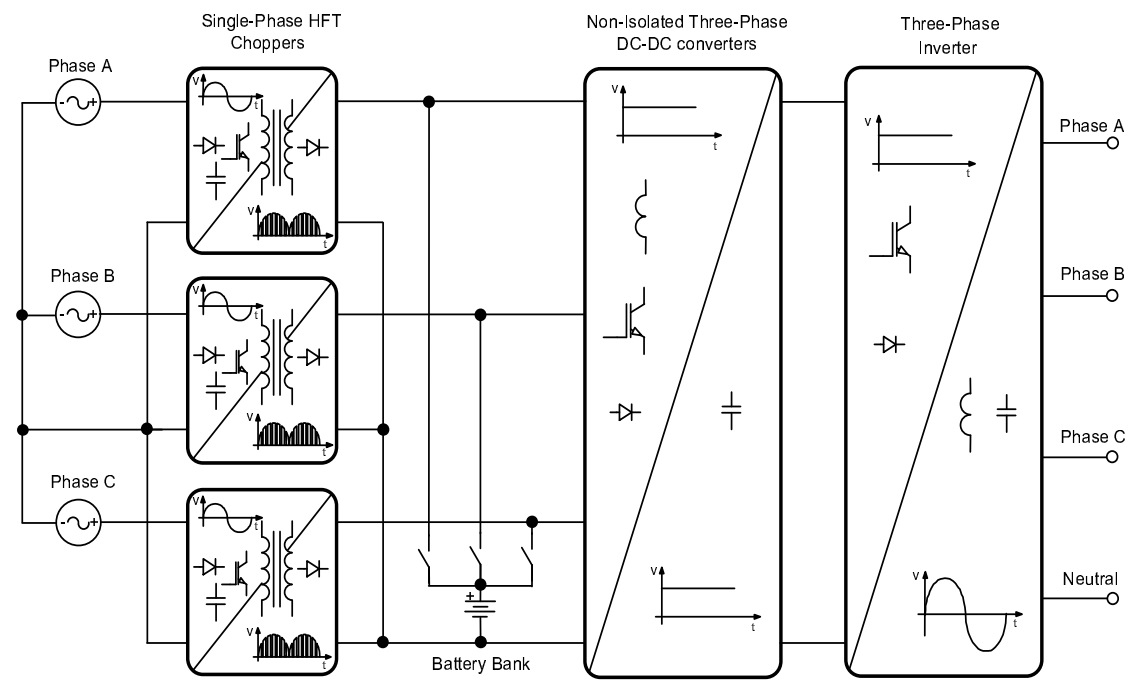

Fig. 1. Simplified block diagram of a three-phase high frequency isolated UPS with the battery bank connected in the secondary side of the HFT.

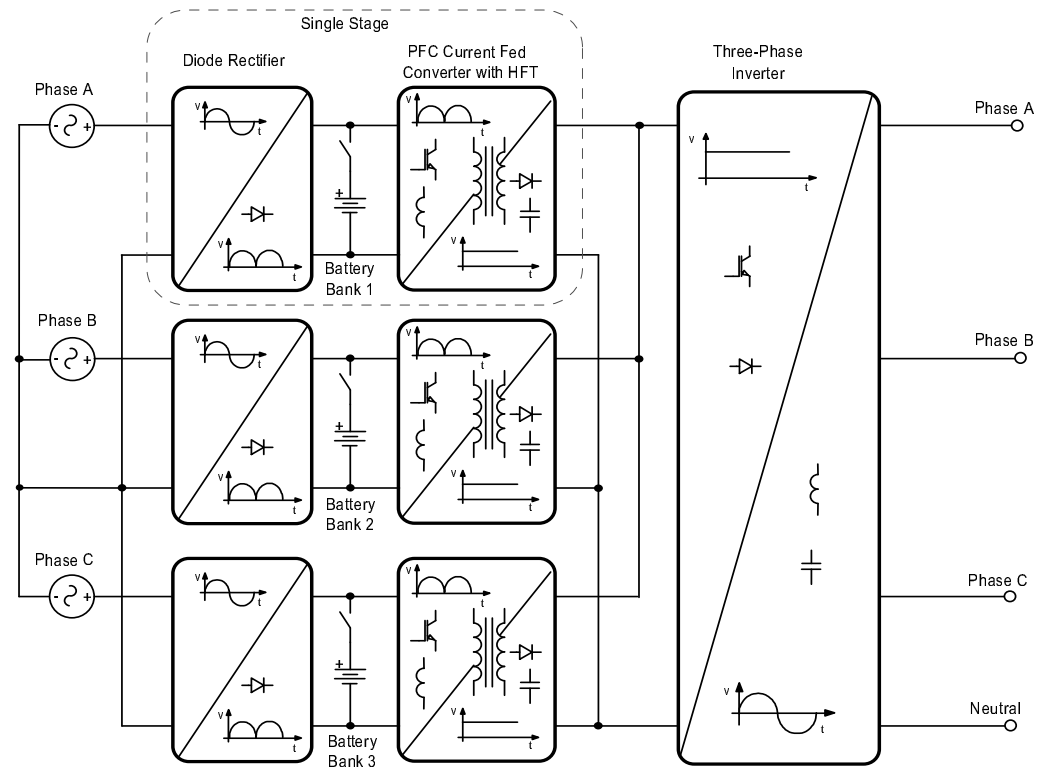

Fig. 2. Simplified block diagram of a three-phase high frequency isolated UPS with the battery bank connected in the primary side of the HFT. 
Also considering the block diagrams, two arrangements are proposed to connect the battery bank in a HFT UPS.

The first one shown in Figure 1 consider the battery bank connected in the secondary side of the HFT and the other one shown in Figure 2 consider the battery bank connected in the primary side of the HFT. The idea in both proposals was to use the same online power converter to raise the battery bank voltage up to a suitable voltage level. The concept proposed in Figure 1 presents the advantage of only one required battery bank and higher efficiency due to the reduced amount of power processing devices that operates in the battery powered mode. However, in this case the battery bank is non-isolated from the load and it could be a drawback when a fault occurs in the semiconductors of the power stage, and as a result a de voltage could be applied to the load.

The second concept shown in Figure 2 presents the advantage of the battery bank isolation from the load. However, the efficiency is compromised in the battery powered mode and it is required three separated battery banks due to the different references connections in the primary side. If this concept were adopted the battery charger required must have three-isolated outputs or three-isolated battery chargers. Such options must be carefully evaluated.

Considering as reference the block diagrams shown in Figures 1 and 2, several three-phase HFT UPS topologies could be obtained by choosing the classical converters shown in Figures 3, 4, 5 and 6.

Thus, a topology example based in the first concept is shown in Figure 7. This topology was chosen to be further analyzed in this work due to its relevant characteristics such as: lower weight and size, modular topology, simple control strategy, only one battery bank with few batteries in series connection, and soft-switching techniques implemented in some power stages.

Another topology example related to the second concept is shown in Figure 8 and will be fully investigated in a future

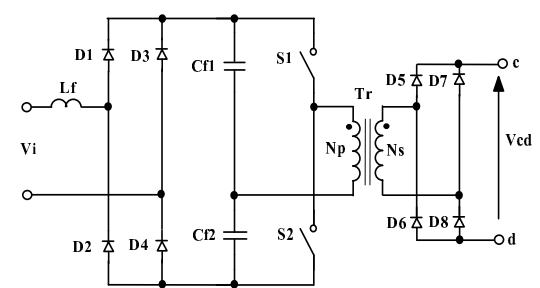

(a)

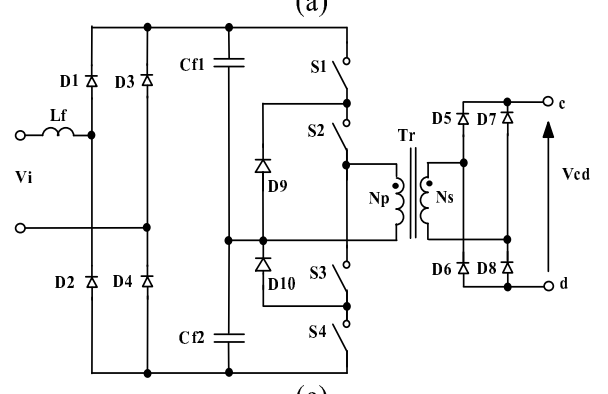

(c)

Fig. 3. Single-phase buck derived chopper circuits. research. It could be an interesting solution for the on-line operation mode when the grid voltage is under normal conditions, so it could present a higher efficiency for this mode compared to the topology presented in Figure 7.

So, in addition to previously presented topologies other topologies could be generated by the two concepts and others applications could be reached such as SST implementation, by modifying the unidirectional power flow characteristic of such proposals.

By realizing a qualitative analysis of both proposed concepts based on previously descriptions, it could be concluded that the first block diagram which implementation topology is shown in Figure 7, presents more advantages than the second one such as: only one required battery bank and charger, simple control strategy and easier way to implement soft-switching techniques. Then, the first concept is chosen for this analysis and experimental validation.

\section{PROPOSED UPS CIRCUIT}

\section{A. Topology Description}

The proposed UPS shown in Figure 7 is composed by the following converters: three single phase full-bridge choppers, a three-phase boost converter, a three-phase voltage source inverter and a balancing half-bridge leg. The proposed system could operate with either $220 \mathrm{~V}_{\mathrm{ac}}$ or $380 \mathrm{~V}_{\mathrm{ac}}$ line-toline input voltages, and three-phase $220 \mathrm{~V}_{\mathrm{ac}}$ line-to-line output voltage [12], [13].

The operation with two input voltage levels, the cascaded operation of the chopper and the boost stage, and the possibility of achieving soft commutation of the chopper switches using coupled inductors were achieved in [11] and [26]-[28].

\section{B. Chopper Stages}

The three choppers are open-loop controlled using PWM signals generated by the DsPIC microcontroller. The simplified control block diagram is shown in Figure 9.
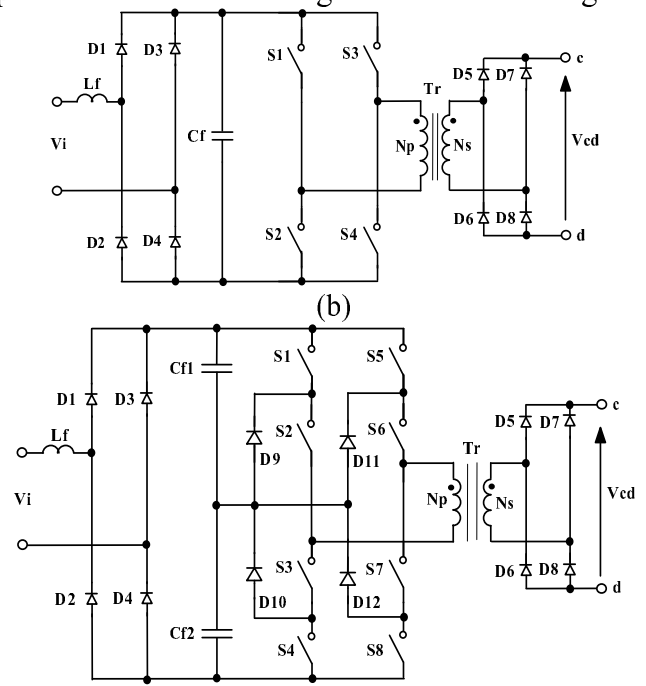

(d) 


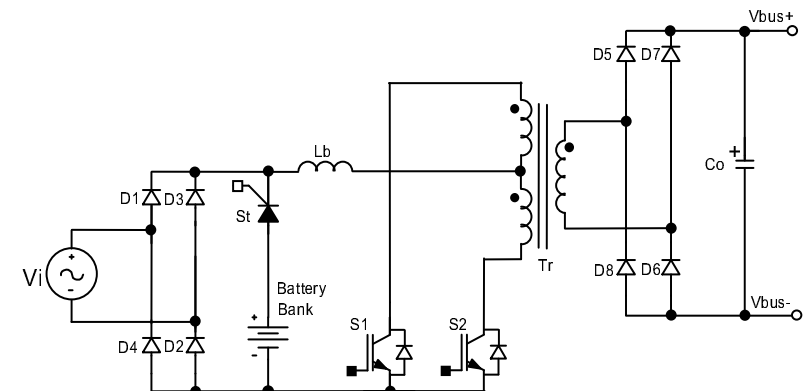

(a)

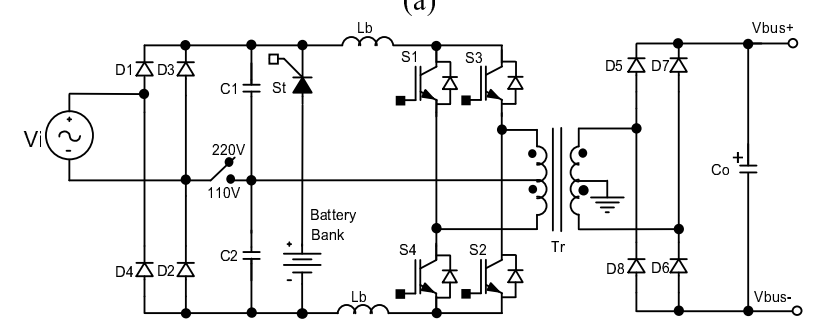

(c)

Fig. 4. Single-phase boost derived chopper circuits.

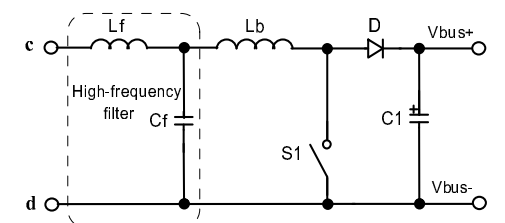

(a)

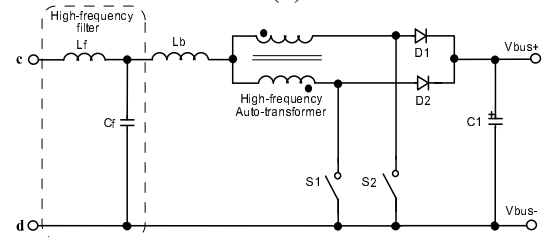

(c)

Fig. 5. Single-phase boost converters.

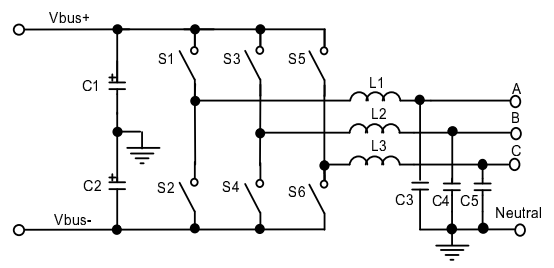

(a)

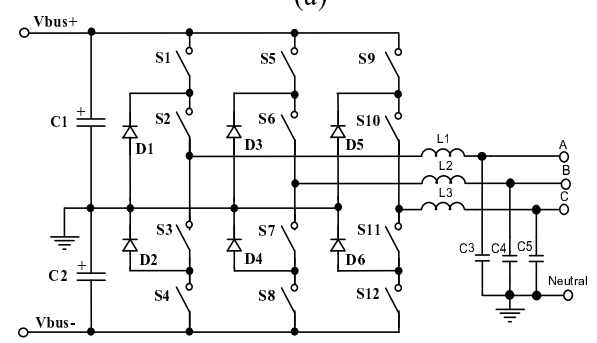

(c)

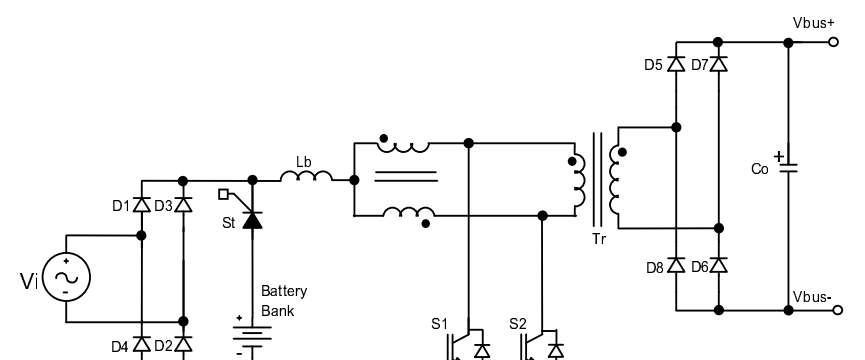

(b)

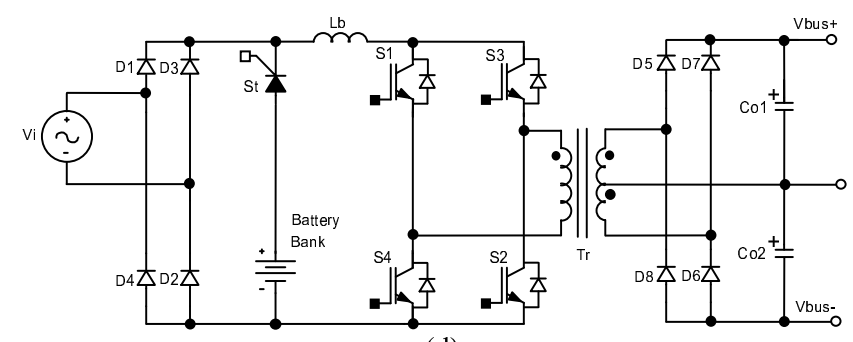

(d)

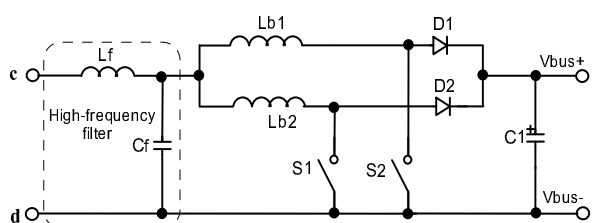

(b)

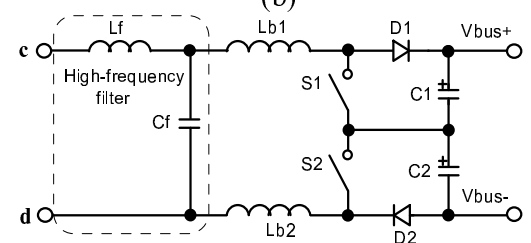

(d)

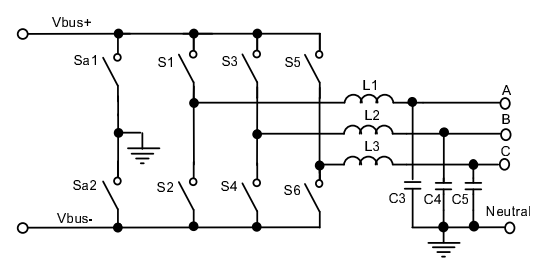

(b)

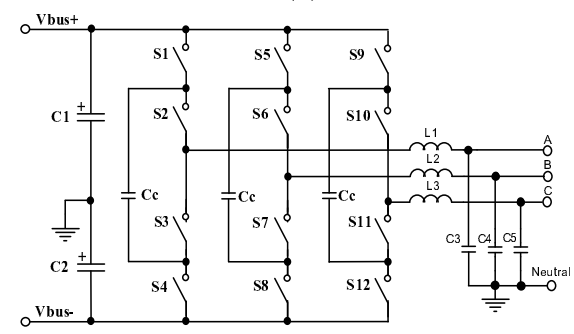

(d)

Fig. 6. Three-phase inverters. 


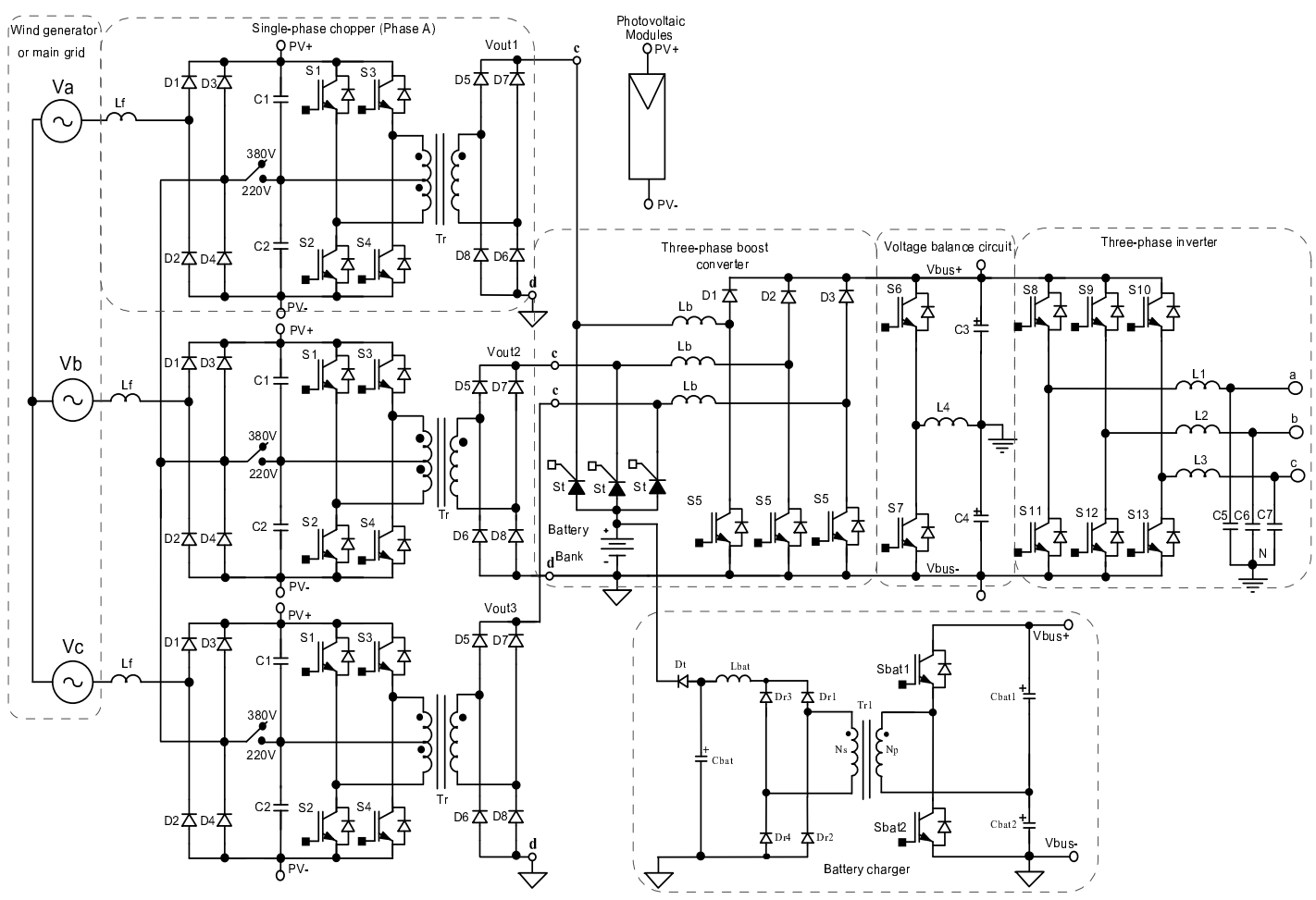

Fig. 7. Proposed three-phase HFT UPS topology based in the block diagram concept shown in Figure 1.

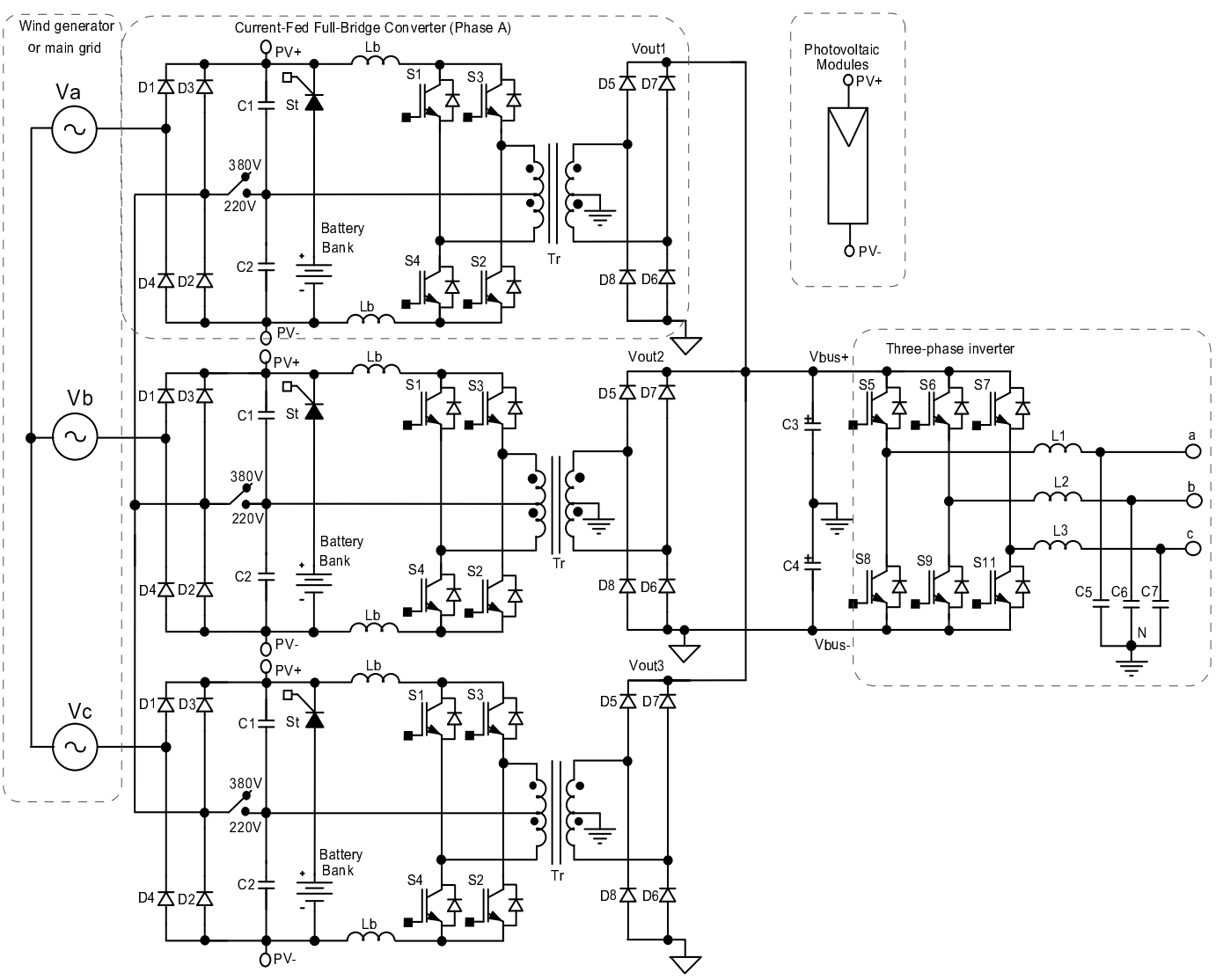

Fig. 8. Proposed three-phase HFT UPS topology based in the block diagram concept shown in Figure 2.

The simultaneous operation of the choppers allows the current sharing through the modules due to the implemented control strategy in the boost stage that is closed loop controlled.
The choppers controlled switches are driven with fixed duty cycle $(\mathrm{D} \cong 0.5)$. The control strategy allows the application of high frequency voltage pulses to the primary windings of the isolation transformer $T_{r}$, enabling the use of a 


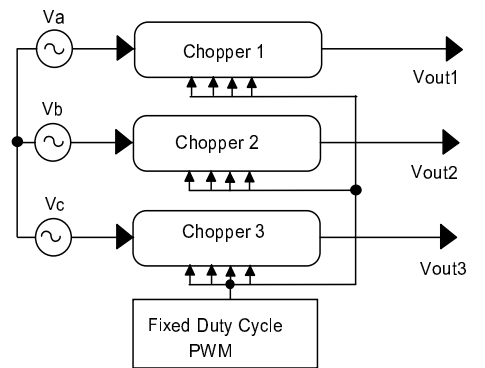

Fig. 9 Control block diagram of the chopper stages.

high frequency transformer. The choppers must be designed using the mathematical theory presented in [11].

\section{Boost Stages}

The three-phase boost converter module is connected to the output of the choppers, and is controlled using conventional average current mode control implemented with the well-known PWM IC UC3854B [29]. Each phase of the boost converter is controlled using your own IC, shown in Figure 10. The voltage reference is obtained from input lineto-neutral voltages. In order to provide a good current sharing and operation stability through the boost circuits, the sawtooth of each integrated circuit are synchronized.

Using this current control technique, the power delivery by each phase is equal, then the neutral displacement voltage is zero and the system will not present any over or under voltages [25].

The three-phase boost converter main functions are: the power flow control in each input phase module, the dc-link bus voltage $V_{b u s}$ control, power factor correction, and stepping up the battery voltage up to the dc-link bus voltage.

Additionally, this stage provides an active filtering to block the pulsating current of the nonlinear load (i.e. the inverter stage) from the battery bank.

\section{Voltage Balancing Control Circuitry}

When three-phase voltage source inverters are used to fed non-linear loads, the output neutral point of the wye, must be

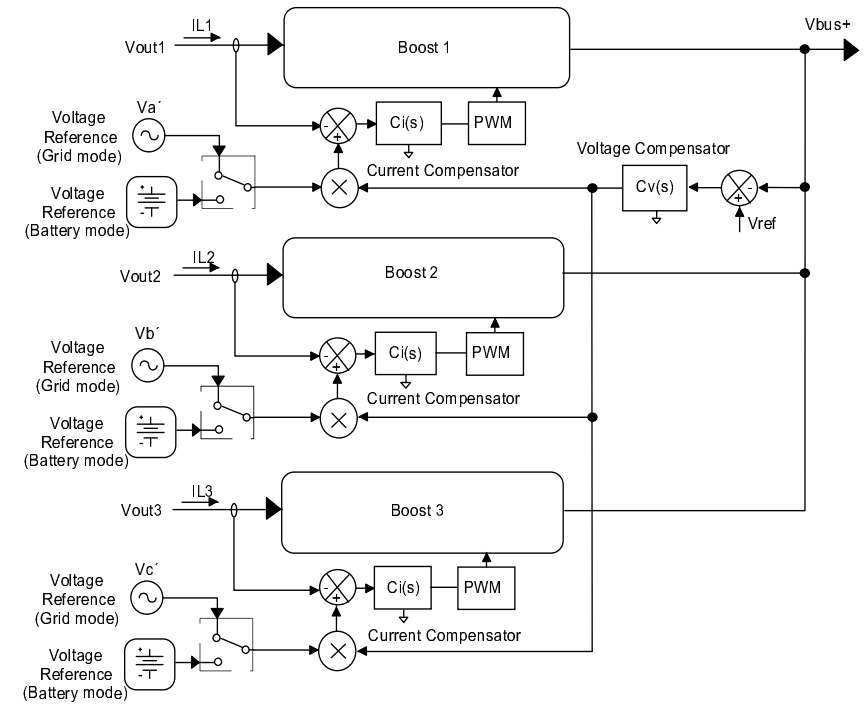

Fig. 10 Control block diagram of the boost stages. connected to the middle point generated by two capacitors in series connection, as shown in Figure 7. The indicated capacitors are unbalanced when an asymmetrical non-linear load is connected to the output of the inverter. To regulate the voltage across the capacitors $\mathrm{C} 3$ and $\mathrm{C} 4$, it is used an auxiliary circuit, which is also shown in Figure 7. The auxiliary circuit is a bidirectional buck converter. The control block diagram of the balancing circuit is shown in Figure 11. The balance circuit has a ground in the middle point of the capacitors, which is also the neutral point of the inverter. The voltages are sampled across the both capacitors and send to the adder, and the resultant signal is compared with a null voltage.

The error signal is send to the compensator and the control voltage is compared with separate two triangular carriers as shown in Figure 11. Compared to the utilization of the fourleg voltage source inverters [30] used for the same purpose in literature, it presents the same number of active switches, and the current circulating through the controlled switches is lower. Thus, it results in a higher efficiency and a simple control circuit implementation.

\section{E. Three Phase Inverter Stage}

In this application a three-phase voltage source inverter is chosen due to its modularity, conventional control implementation and operation [31]. This power stage is also shown in Figure 7.

The control block diagram is shown in Figure 12. The line-to-neutral voltage per phase is sampled and controlled using your own compensator circuitry. The reference voltage of each phase has the same amplitude and is phase-shift from each other in $120^{\circ}$. This reference voltage signals are generated using a quadruple 8-bit digital-to-analog converter with serial interface (TLC5620), controlled by a DsPIC microcontroller and synchronized with the utility voltage [32].

\section{F. Battery Charger Stage}

The battery charger is based on isolated half-bridge DCDC converter, as shown in Figure 7. The converter operates in continuous conduction mode (CCM) of the current through the filter inductor, and is supplied by the dc-link bus capacitors. The control scheme of the battery charger is shown in Figure 13. The implemented control has one voltage and one current control compensator, where, both operates using the OR logic. In this application the battery is charged under constant current controlled by the current regulator.

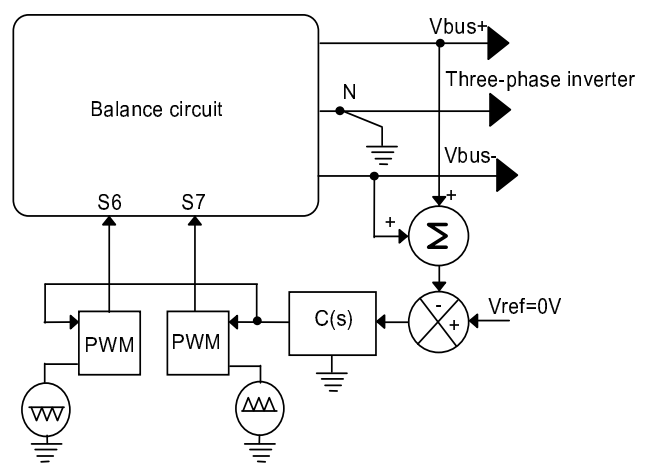

Fig. 11 Control block diagram of the balancing circuit. 


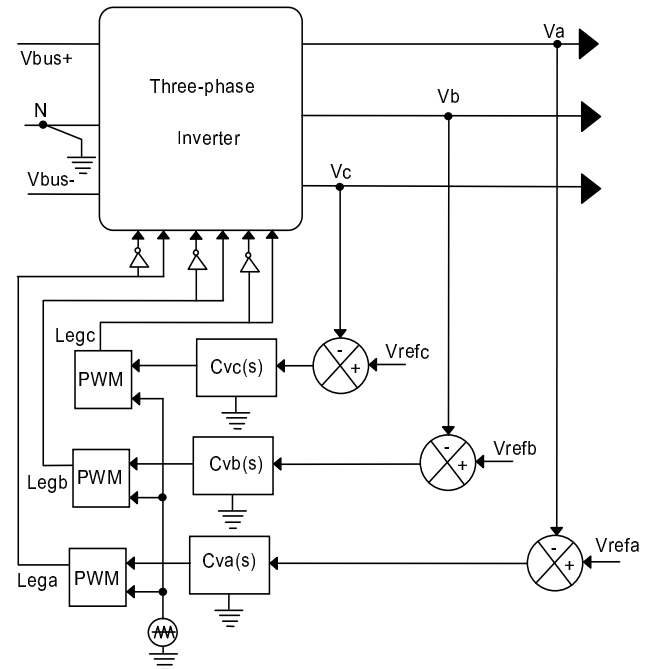

Fig. 12 Control block diagram of the three-phase inverter.

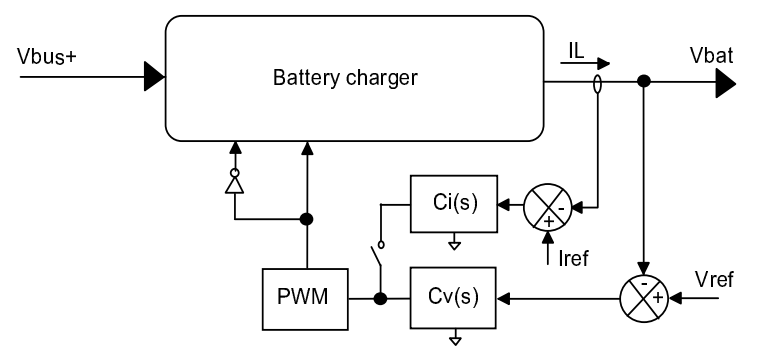

Fig. 13 Battery charger control block diagram.

For this application, a thyristor St associated with a passive snubber was used to connect the battery bank thought the on-line power circuitry during the battery powered mode. Switch $S t$ is turned on when the ac mains voltage is null or out of the input voltage range and it is turned off when ac mains voltage is within the desired limits.

\section{EXPERIMENTAL RESULTS}

\section{A. Developed System Specifications}

The proposed UPS concept is verified in experimental prototype with main specifications shown in Table I. The switching frequency for the chopper and boost stage modules is assumed $f_{s}=30 \mathrm{kHz}$. The switching frequency for the threephase inverter stage is assumed $\mathrm{f}_{\mathrm{s}}=20 \mathrm{kHz}$.

A photograph of the experimental prototype is shown in Figure 14. As can be seen, it is divided into four levels: from top to bottom are shown the three-phase inverter power and control circuitry, the magnetic components used in the threephase inverter, the chopper-boost phase modules and control, and finally the magnetic components used in the chopperboost modules.

The battery bank isn't shown in this figure and it's supposed to be mounted in an external rack. In this first assembly the main objective was to validate the topology.

A second project is still in progress in order to design a compactness assembly with the power modules mounted in a rack type structure and optimization of magnetics devices and adopted semicondutors.
TABLE I

Developed Three-Phase HFT UPS Specifications

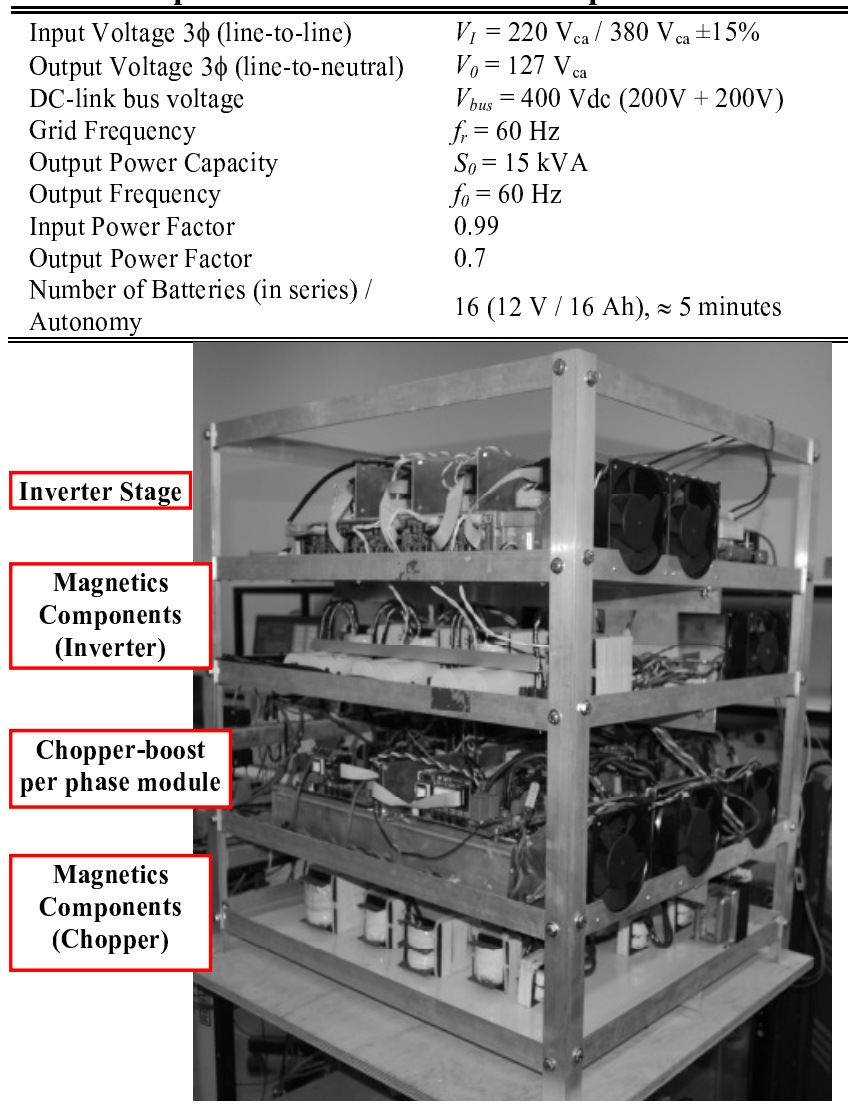

Fig. 14. Photograph of the assembled prototype.

The experimental waveforms were made considering the UPS operating under grid or battery powered operation. It consists of relevant voltages waveforms, currents waveforms and measurements collected from the proposed UPS. The grid mode operation experimental results were realized for two different input voltages levels.

The results shown in Figures 15-18 were obtained for an input line-to-line voltage equal to $380 \mathrm{Vac}$ and the results shown in Figures 19-22 were obtained for an input line-toline voltage equal to $220 \mathrm{Vac}$. The three-phase non-linear load used for the tests complies with the requirements of IEC62040-3 [33].

\section{B. Waveforms for the Grid and Battery Mode Operation (line-to-line input voltage of $380 \mathrm{~V}_{a c}$ )}

In this section is presented the experimental waveforms regarding the grid mode and battery mode operation, for the line-to-line input voltage equal to $380 \mathrm{~V}_{\mathrm{ac}}$.

Figure 15 shows the line currents and line-to-neutral input voltage of phase "a". The measured harmonic content of the input currents is equal to $8.5 \%$ for this case. It can be observed that the input current is close to sinusoidal and has an almost unity input power factor.

Figure 16 shows the voltage behavior across the dc-link capacitors $\mathrm{C} 3$ and $\mathrm{C} 4$. It can be seen that both voltages are almost the same. Thus, the voltage balance converter is working as expected, as well as the boost voltage regulation, because the sum of the two voltages is equal to the total dclink voltage $(400 \mathrm{Vdc})$. 
The output current of phase "b" and line-to-neutral output voltages are shown in Figure 17, where a high quality sinusoidal voltage waveform is obtained. It can be seen that the rms voltage values are regulated as specified in Table I. The current shape defines the load type as informed before. The measured harmonic content of the outputs voltages waveforms is equal to $3.5 \%$.

The utility input current for one phase, the battery current, as well as the output voltage waveform for one phase is show in Figure 18, when occurs the UPS transition from grid mode to battery mode. During the battery mode it can be seen that the battery current is almost continuous with a lower ripple. Notice that the load voltages continue to regulate despite the ac main failures.

The three-phase UPS conversion efficiency was measured with Yokogawa PZ4000 power analyzer. It reached an overall efficiency of almost $87 \%$ for the grid mode operation, and $90 \%$ for the battery mode operation. This efficiency measurement includes consideration of the control power and battery charger power while operating in fluctuation mode.

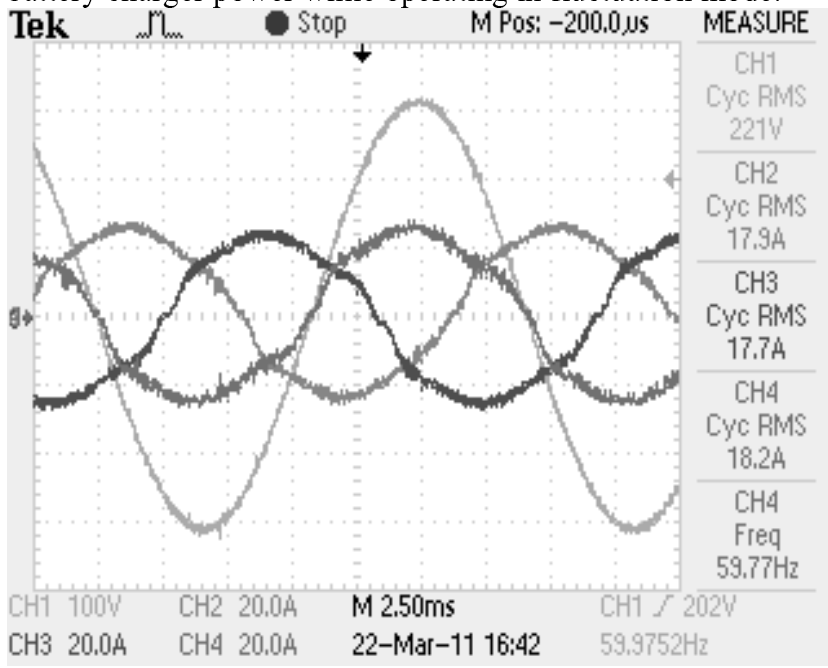

Fig. 15. Line currents and line-to-neutral input voltage of phase "a". Operation in 380 Vac. (Ch1:100V/div., Ch2:20A/div., Ch3:20A/div., Ch4:20A/div., 2.5ms/div.)

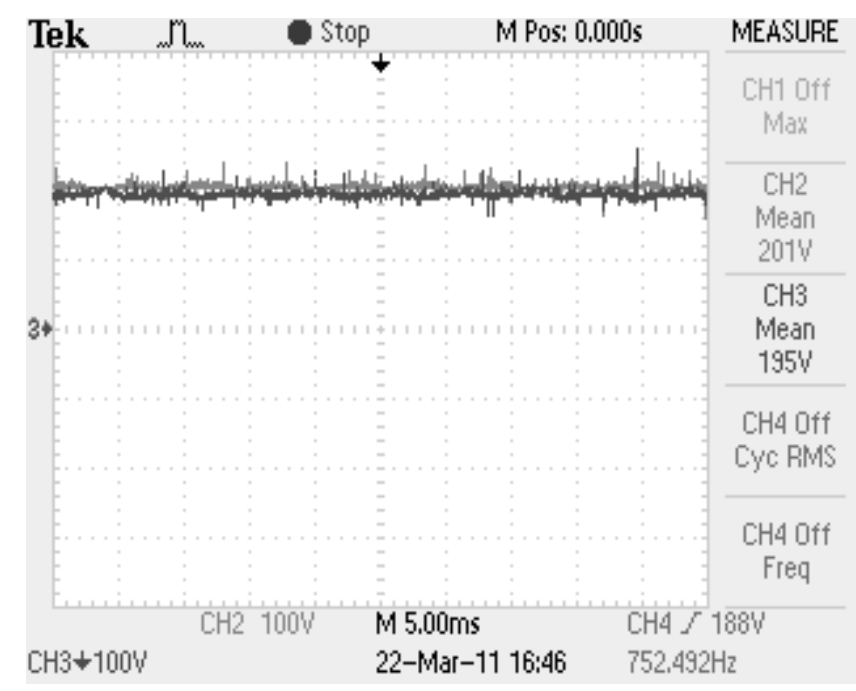

Fig. 16. DC-link bus capacitors voltages. Operation in 380 Vac. (Ch2:100V/div.; Ch3:100V/div.; 5ms/div.)

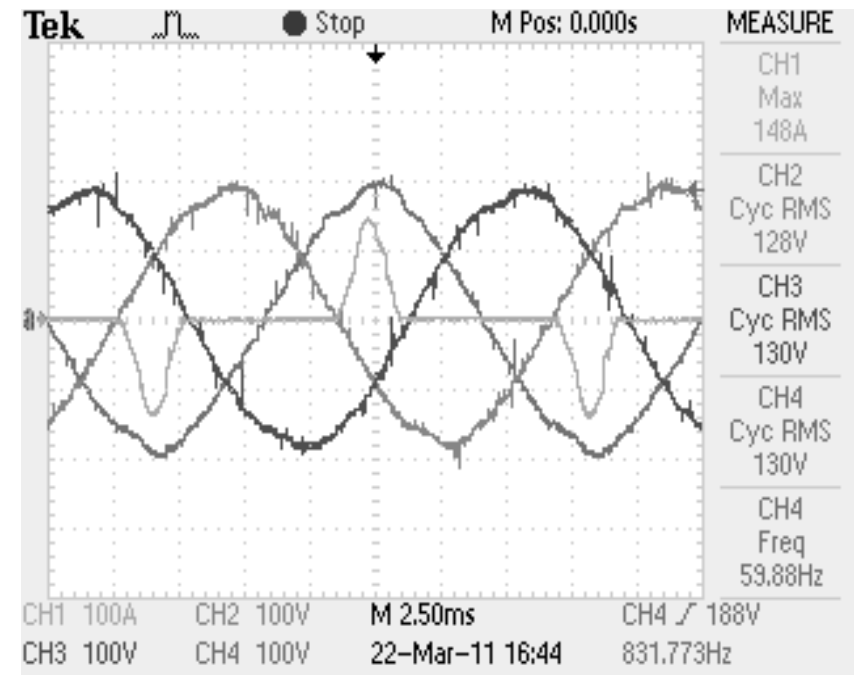

Fig. 17. Output current of phase "b" and line-to-neutral output voltages. Operation in 380 Vac. (Ch1:100A/div., Ch2:100V/div., Ch3:100V/div., Ch4:100V/div., 2.5ms/div.)

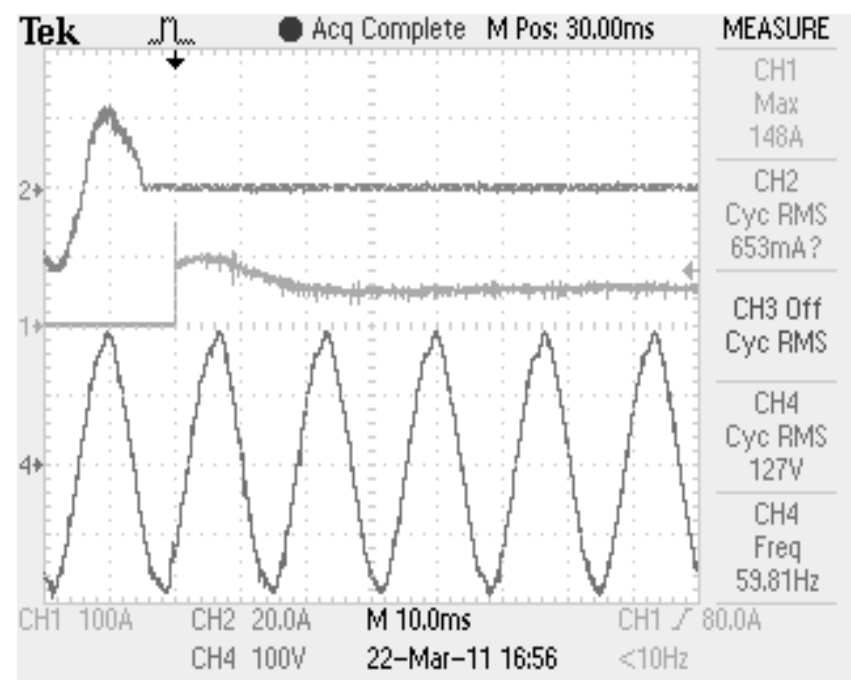

Fig. 18. UPS transition from grid mode operation to battery mode. From top to bottom: input current (one phase), battery current and output voltage (one phase). (Ch1:100A/div.; Ch2:20A/div., Ch4:100V/div.; $10 \mathrm{~ms} /$ div.)

\section{Waveforms for the Grid and Battery Mode Operation (line-to-line input voltage of $220 \mathrm{~V}_{a \mathrm{c}}$ )}

In this section is presented the experimental waveforms regarding the grid mode and battery mode operation, for the line-to-line input voltage equal to $220 \mathrm{~V}_{\mathrm{ac}}$.

Figure 19 shows the line currents and line-to-neutral input voltage of phase "a". The measured harmonic content of the input currents is equal to $8.0 \%$ for this case. It can be observed that the input current presents almost the same behavior as operating with input voltage equal to $380 \mathrm{~V}_{\mathrm{ac}}$. Thus, this is a relevant characteristic of this converter that could be used for a flexible input voltage range.

Figure 20 shows the voltage behavior across the dc-link capacitors $\mathrm{C} 3$ and $\mathrm{C} 4$. The well-controlled voltage across the capacitors verifies that the voltage balancing circuit works effectively. 


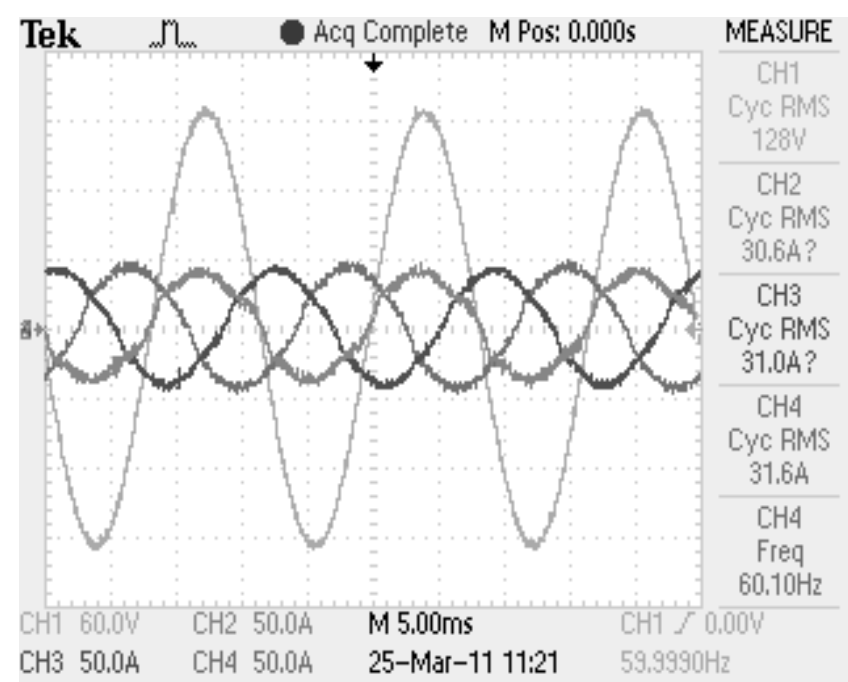

Fig. 19. Line current of phase "a" and line-to-neutral input voltages. Operation in 220 Vac. (Ch1:60V/div., Ch2:50A/div., Ch3:50A/div., Ch4:50A/div., $5 \mathrm{~ms} /$ div.)

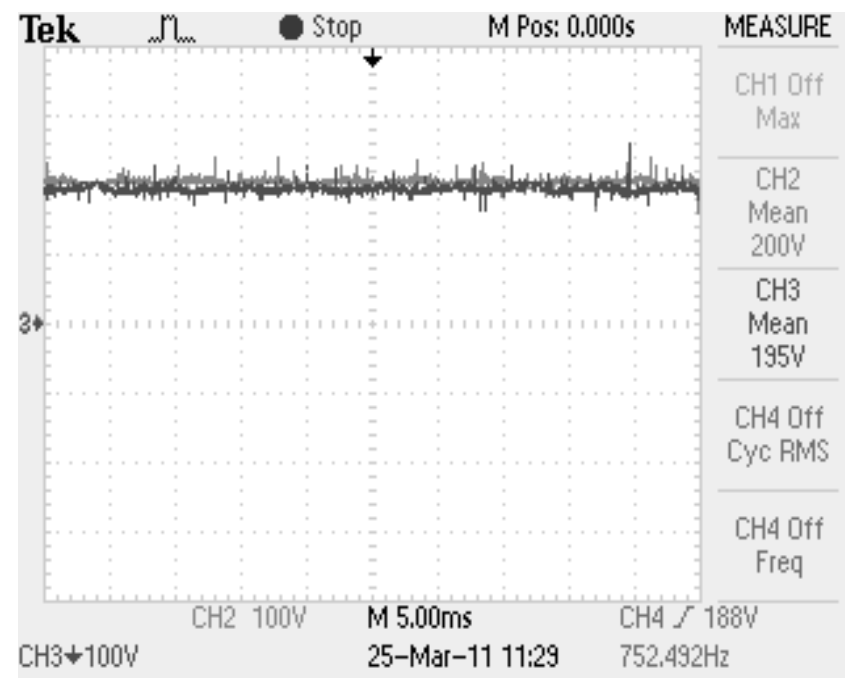

Fig. 20. DC-link bus capacitors voltages. Operation in 220 Vac. (Ch2:100V/div.; Ch3:100V/div.; 5ms/div.)

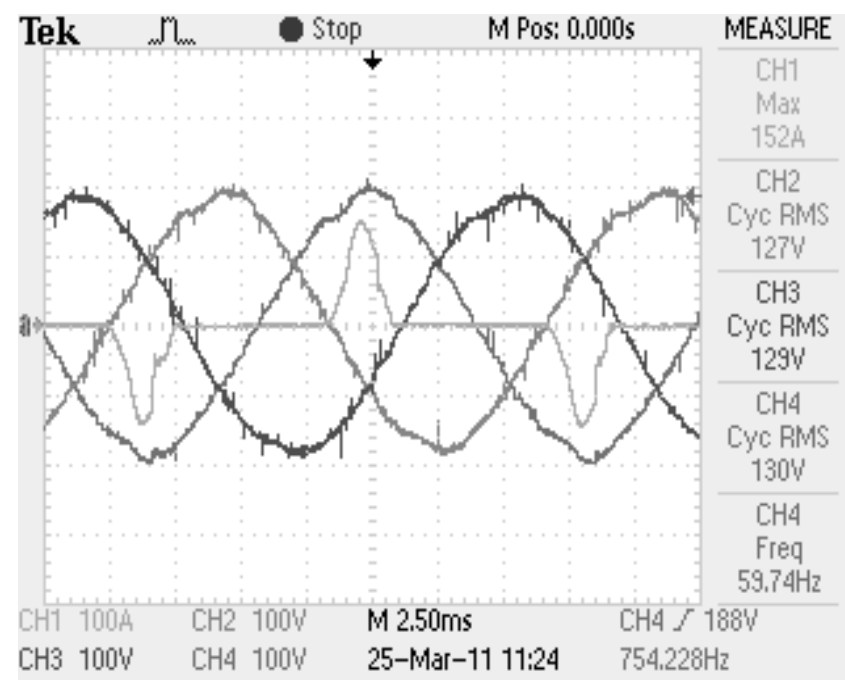

Fig. 21. Output current of phase "b" and line-to-neutral output voltages. Operation in 220 Vac. (Ch1:100A/div., Ch2:100V/div., Ch3:100V/div., Ch4:100V/div., $2.5 \mathrm{~ms} /$ div.)

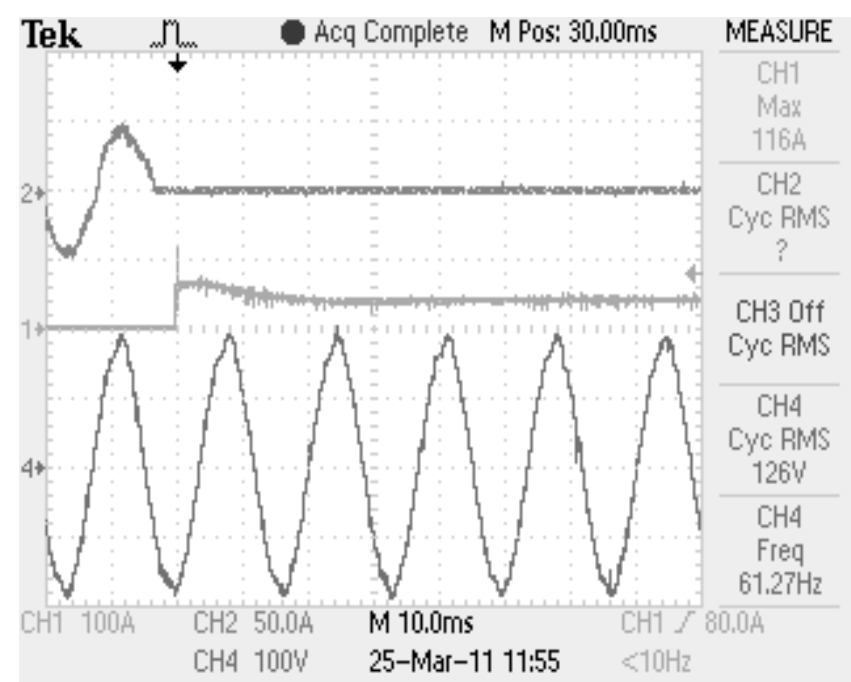

Fig. 22. UPS transition from grid mode operation to battery mode. From top to bottom: input current (one phase), battery current and output voltage (one phase). (Ch1:100A/div.; Ch2:50A/div., Ch4:100V/div.; 10ms/div.)

Figure 21 shows the output current of phase " $b$ " and lineto-neutral output voltages, where a high quality sinusoidal voltage waveform is also obtained for this operating condition. The output voltage in each phase is regulated in the desired rms value and the measured harmonic content of the outputs voltages waveforms is equal to $3.2 \%$.

Figure 22 depicts the utility input current for one phase, the battery current, as well as the output voltage waveform for one phase, when occurs the UPS transition from grid mode to battery mode. It can be seen that the proposed system presents almost the same behavior operating with different input voltages. The load voltages continue to regulate despite the ac main failures.

The measured efficiency while operating with a line-toline input voltage equal to $220 \mathrm{~V}_{\mathrm{ac}}$ is almost $86 \%$ for the grid mode operation, and $90 \%$ for the battery mode operation.

Accordingly to the experimental results this system has a reasonable efficiency due to the lower cost components used for experimental validation. Therefore, the aim of further future research will be an optimization of the prototype, by investigating where is located each power losses and making improvements in the specification and design of semiconductors and magnetics components.

Furthermore, the establishment of guidelines for the threephase UPS dimensioning and a more detailed experimental analysis are planned with others topologies based in this concept.

\section{CONCLUSIONS}

This paper proposed some three-phase high frequency transformer (HFT) UPS topologies suitable to supply a wide variety of critical loads or for other applications purpose such as energy storage or power conditioning applications in high power density distributed generation (DG) systems. The concept could be used with the grid source or connected to renewable energy sources such as wind generator or photovoltaic modules. The proposal could also be extended 
for SST applications by using bidirectional converters in the rectifier modules.

The viability and effectiveness of the three-phase HFT UPS has been verified by a $15-\mathrm{kVA}$ laboratory system. Accordingly to the experimental results for a particular chosen topology the system has the following advantages: modular power converters, simple control circuit, few batteries in series connection, power factor correction, sinusoidal output voltages when supplying nonlinear loads and lower weight and size. As disadvantages of such concept is the higher number of semiconductors that lowers its reliability, and reasonable power converter efficiency that was measured higher than $86 \%$ for both input voltages in the grid mode, and higher than $90 \%$ for the battery mode.

The aim of a future research will be an optimization of the current prototype and realize an investigation of the topology proposed in Figure 8, in other to make a comparative and comprehensive analysis between the two proposals.

\section{ACKNOWLEDGEMENT}

Authors would like to thank CM Comandos Lineares for providing financial support for development work.

\section{REFERENCES}

[1] J. M. Guerrero, F. Blaabjerg, T. Zhelev, K. Hemmes, E. Monmasson, S. Jemei, M. P. Comech, R. Granadino, J. I. Frau, "Distributed Generation: Toward a New Energy Paradigm”, IEEE Industrial Electronics Magazine, vol. 04, no. 1, pp. 52-64, March 2010.

[2] K. Alanne and A. Saari, "Distributed energy generation and sustainable development", Renewable and Sustainable Energy Reviews, vol. 10, no. 6, pp. 539-558, December 2006.

[3] J. M. Guerrero, L. Hang, and J. Uceda, "Control of distributed uninterruptible power supply systems", IEEE Transactions on Industrial Electronics, vol. 55, no. 8, pp. 2845-2859, August 2008.

[4] J. M. Guerrero, J.C. Vasquez, J. Matas, M. Castilla, L. G. de Vicuna, "Control Strategy for Flexible Microgrid Based on Parallel Line-Interactive UPS Systems", IEEE Transactions on Industrial Electronics, vol. 56, no. 3, pp. 726-736, March 2009.

[5] J. M. Guerrero, L. G. Vicuna, J. Uceda, "Uninterruptible power supply systems provide protection", IEEE Industrial Electronics Magazine, vol. 01, no. 1, pp. 2838, Spring 2007.

[6] F. Botterón and H. Pinheiro, "A High Performance Synchronous Frame Internal Model-Based Controller for Three-Phase Double-Conversion UPS that Complies with the Standard IEC62040-3", Eletrônica de Potência - SOBRAEP, vol. 11, no. 2, pp. 135-147, July 2006.

[7] E. H. Kim. J. M. Kwon, J. K. Park, and B. H. Kwon, "Practical Control Implementation of a Three- to SinglePhase Online UPS", IEEE Transactions on Industrial Electronics, vol. 55, no. 8, pp. 2933-2942, August 2008.
[8] C. G. C. Branco, C. M. T. Cruz, R. P. Torrico-Bascopé, F. L. M. Antunes, "A Non-isolated Single Phase Ups Topology With 110v/220v Input Output Voltage Ratings", Eletrônica de Potência - SOBRAEP, vol. 11, no. 2, pp. 111-118, July 2006.

[9] C.-C. Yeh, and M. D. Manjrekar, "Reconfigurable uninterruptible power supply system for multiple power quality applications", IEEE Transactions on Power Electronics, vol. 22, no. 4, pp. 1361-1372, July 2007.

[10] I. Gunes, B. Ustuntepe, A. M. Hava, "Modern transformerless uninterruptable power supply (UPS) systems", in Proc. of Int. Conf. Elect. Electron. Eng. (ELECO), pp. 316-320, 2009.

[11] R. P. Torrico-Bascopé, D. S. Oliveira Jr., C. G. C. Branco, F. L. M. Antunes, "A High Frequency Transformer Isolation Ups System With $110 \mathrm{v} / 220 \mathrm{v}$ Input Voltage", Eletrônica de Potência - SOBRAEP, vol. 11, no. 3, pp. 239-247, November 2006.

[12] R. P. Torrico-Bascopé, C. G. C. Branco, C. M. T. Cruz, G. F. S. Filho, L. D. Bezerra, "Three-phase 15kVA UPS System with Power Factor Correction and High Frequency Transformer Isolation", in Proc. of COBEP, pp. 1200-1207, 2009.

[13] R. P. Torrico-Bascopé, C. G. C. Branco, C. M. T. Cruz, L. D. S. Bezerra, G. A. T. Hertz, "Three-phase UPS with high power factor and high frequency transformer isolation", in Proc. of IEEE Ind. Electron., Control and Instrumentation Conf., pp. 919-924, 2009.

[14] D. De, V. Ramanarayanan, "High frequency link topology based double conversion UPS system", in Proc. of Int. Conf. Power Elect, Drives and Energy Syst. (PEDES), pp. 1-6, 2010.

[15] A. Nasiri, N. Zhong, S. B. Bekiarov, A. Emadi, "An OnLine UPS System With Power Factor Correction and Electric Isolation Using BIFRED Converter", IEEE Transactions on Industrial Electronics, vol. 55, no. 2, pp. 722-730, February 2008.

[16] N. Vazquez, J. Villegas-Saucillo, C. Hernandez, E. Rodriguez, and J. Arau, "Two stage uninterruptible power supply with high power factor", IEEE Transactions on Industrial Electronics, vol. 55, no. 8, pp. 2954-2962, August 2008.

[17] R. Yamada, et al. "High-frequency isolation UPS with novel SMR", in Proc. of IEEE Ind. Electron., Control and Instrumentation Conf., vol. 02, pp. 1258-1263, 1993.

[18] W. Jun; A. Huang, S. Woongje, L. Yu, J. B. Baliga, "Smart Grid Technologies", IEEE Industrial Electronics Magazine, vol. 03, no. 2, pp. 16-23, June 2009.

[19] J. W. Kolar, H. Ertl, and F. C. Zach, "A Novel Threephase single switch discontinuous-mode AC-DC buckboost converter with high quality input current waveform and isolated output", IEEE Transactions on Power Electronics, vol. 9, no. 2, pp. 160-172, March 1994.

[20] O. Opeldoorn and P. Schmidt, "Single transistor threephase power conditioner with high power factor and isolated output", in Proc. of IEEE Applied Power Elec. Conf., pp. 731-737, 1994. 
[21] R. Y. Igarashi and I. Takahashi, "Unit power factor three-phase dither rectifier using a single switched device", in Proc. of IEEE Ind. Applicat. Soc. Conf., vol. 2, pp. 769-779, 1994.

[22] J. A. Pomilio and G. Spiazzi, "High-precision current source using low-loss, single switch three-phase AC/DC converter", IEEE Transactions on Power Electronics, vol. 11, no. 4, pp. 561-566, July 1996.

[23] J. W. Kolar, U. Drofenik, and F. C. Zach, "VIENNA rectifier II-a novel single-stage high-frequency isolated three-phase PWM rectifier system", IEEE Transactions on Industrial Electronics, vol. 46, no. 4, pp. 674-691, August 1999.

[24] D. C. Martins and E. S. de Andrade, "Unidade Retificadora Trifásica Isolada com Alto Fator de Potência", Eletrônica de Potência - SOBRAEP, vol. 7, no. 1, pp. 46-53, November 2002.

[25] M. L. Heldwein, A. F. de Souza, and I. Barbi, "Threephase Rectifier Unit For Telecommunication Applications Using Single-phase Rectifier Modules", in Proc. of COBEP, pp. 235-240, 1999.

[26] G. V. Torrico-Bascopé and I. Barbi, "Single-phase high power factor variable output voltage rectifier, using the buck+boost converter: control aspects, design and experimentation", in Proc. of COBEP, pp. 143-148, 1999.

[27] R. Torrico-Bascopé and I. Barbi, "Dual-bridge DC-DC converter with soft Switching Features", in Proc. of IEEE Appl. Power Electron. Conf., vol. 02, pp. 722-727, 2001.

[28] F. K. A. Lima, C. M. T. Cruz, F. L. M. Antunes, "A High Efficiency Unit Power Factor Single-phase Rectifier", in Proc. of COBEP, pp. 891-896, 2003.

[29] Philip C. Todd, UC3854 Controlled power factor correction circuit design, Unitrode Application Notes U134, pp. 3-269 - 3-288, 1994.

[30] O. Ojo, P.M. Kshirsagar, "Concise modulation strategies for four-leg voltage source inverters", IEEE Transactions on Power Electronics, vol. 19, no. 1, pp. 46-56, January 2004.

[31] D. C. Martins and I. Barbi, Introduction to the Study of $D C-A C$ Converters. Author's Edition, pp. 375-430, 2005.

[32] R. W. Wall, "Simple methods for detecting zero crossing", in Proc. of IEEE Ind. Electron., Control and Instrumentation Conf., pp. 2477-2481, 2003.

[33] Uninterruptible Power Systems (UPS)_Part 3: Method of Specifying the Performance and Test Requirements, First Edition 1999-03, International Standard IEC 62040-3.

\section{BIOGRAPHIES}

Carlos Gustavo Castelo Branco was born in Fortaleza, Ceará, Brazil, on July $11^{\text {th }}, 1979$. He received the B. Sc. And M. Sc degrees in Electrical Engineering from Federal University of Ceará, Brazil, in 2002 and 2005, respectively. Currently, he is working towards the Dr. Eng. degree in Electrical Engineering from Federal University of Ceará, Brazil. Since 2009, he has been with the Electrical Engineering Department, Federal University of Ceará (Brazil), where he is now Professor of Electrical Engineering. His research interests include uninterruptible power supply systems, power factor correction circuits, softswitching techniques and converters for renewable energy sources. He is member of the Brazilian Society of Power Electronics (SOBRAEP) and the Institute of Electrical and Electronics Engineers (IEEE).

René Pastor Torrico-Bascopé was born in Cochabamba, Bolivia, in 1967. He received the B. Eng. degree from San Simón University of Cochabamba, Bolivia, in 1992, and its M.Eng. and Dr.Eng. degrees from the Federal University of Santa Catarina, Florianópolis, Brazil, in 1994 and 2000, respectively.

During 1995 and 1996, he was Research Engineer in the Power Electronics Institute of the Federal University of Santa Catarina. From March 2001 to May 2003, he has been an Assistant Professor at the Univali University of Itajaí, Brazil. Currently, he is Associate Professor of the Department of Electrical Engineering of the Federal University of Ceará, Brazil. His main research interests include power supplies, power factor correction techniques, UPS systems, and alternative energy systems.

Cícero Marcos Tavares Cruz was born in Crato$\mathrm{CE}$ (Brazil). He received the B.Sc. in Electrical Engineering from the Federal University of Ceará in 1990. He received the MSc and Dr.Eng. degrees in Electrical Engineering from Federal University of Santa Catarina, Brazil, in 1993 and 2002, respectively. Since 1994, he has been with the Electrical Engineering Department, Federal University of Ceará (Brazil), where he is now Associate Professor of Electrical Engineering. His research interests include Power Electronics and its application to renewable energy. He is member of the Brazilian Society of Power Electronics (SOBRAEP).

Francisco Kleber de A. Lima was born in Fortaleza-CE (Brazil). He received the B.Sc. in Electrical Engineering from the Federal University of Ceará in 1998. He received the M. Sc. and Dr. Eng. degrees in Electrical Engineering from Federal University of Ceará, Brazil, and from Federal University of Rio de Janeiro, Brazil, in 2003 and 2009, respectively. Currently, he is with the Electrical Engineering Department, Federal University of Ceará (Brazil), where he is now Adjunct Professor of Electrical Engineering. His research interests include Power Electronics and its application to the power system and renewable energy systems. He is member of the Brazilian Society of Power Electronics (SOBRAEP). 